\title{
CAPÍTULO 90
}

\section{SEXUALIDADE E INFECÇÕES SEXUALMENTE TRANSMISSÍVEIS NA TERCEIRA IDADE}

\section{DOI 10.4322/978-65-995353-2-1.c90}

\author{
Drieli Ferreira Costa ${ }^{1}$, Bruna Stephanie Sousa ${ }^{2}$, Àlvaro da Silva Santos ${ }^{3}$ \\ ${ }^{1}$ Curso de Graduação em Enfermagem/ Universidade Federal do Triângulo Mineiro(UFTM),
}

(enfdrieli@gmail.com)

${ }^{2}$ Programa de Pós Graduação em Atenção à Saúde (PPGAS)/ UFTM,

(b.malaquias@outlook.com)

${ }^{3}$ Curso de Graduação em Enfermagem e PPGAS/Programa de Pós Graduação Stricto Sensu

\section{Resumo}

em Psicologia/ UFTM, (alvaroenf@hotmail.com)

Objetivo: Desenvolver atividades de educação em saúde em uma roda de conversa com idosos para transmitir conhecimentos sobre sexualidade e infecções sexualmente transmissíveis. Método: O trabalho foi desenvolvido por meio de um projeto de extensão da Universidade Federal do Triângulo Mineiro. Trata-se de um grupo de educação em saúde realizado com idosos frequentadores da Unidade de Atenção ao Idoso em Uberaba - Minas Gerais. A atividade contou com 20 encontros que aconteciam semanalmente, durante cinco meses. Foram realizadas dinâmicas e jogos como forma de atração para ser realizado o objetivo de discutir temas importantes acerca de sexualidade e ISTs na terceira idade. Resultados: $\mathrm{O}$ projeto difundiu informações sobre sexualidade pertinentes na terceira idade, criou espaço de acolhimento e participação social, promoveu saúde e trocas de experiências ricas entre os graduandos e os idosos. A partir do conhecimento adquirido, os idosos atingiram autonomia em diversas áreas da vida, melhorando sua qualidade de vida. Considerações Finais: $O$ projeto atingiu o objetivo, mostrando eficácia nas ações de educação em saúde. Foi identificada carência de conhecimento de grande parte dos idosos acerca dos temas estudados, indicando a necessidade de mais ações como estas. Os graduandos que coordenaram as ações aprenderam a mediar discussões em grupo, a elaborar material didático e aprimoraram sua prática com pessoas mais velhas.

Palavras-chave: Sexualidade; Idosos; Infecções Sexualmente Transmissíveis.

Área Temática: Ciências da Saúde.

E-mail do autor principal: enfdrieli@gmail.com

\section{INTRODUÇÃO}

A expectativa de vida mundial está aumentando e os países em desenvolvimento, como o Brasil, tem um grande destaque (BRASIL, 2013). Atualmente, o Instituto Brasileiro de 
Geografia e Estatística (2021) aponta que os idosos com 65 anos ou mais representam 10,15\% da população brasileira, projetando que será 17,41\% em 2040, e em 2060 um expressivo número de $25,49 \%$.

O envelhecimento da população acarreta impactos importantes, gerando mudanças sociais, na previdência e nas áreas da saúde. E apesar do estigma de pessoas envelhecidas serem frágeis, a maioria dos idosos são ativos, possuem papel importante na família, sonham e possuem grande perspectiva de vida (BRASIL, 2013).

Nesse contexto, os idosos necessitam de um olhar especial para que sejam amparados nessa fase da vida. O cuidado deve ser empregado em todas as esferas da vida, e o Estatuto do Idoso garante proteção, acesso à saúde e políticas públicas que permeiam um envelhecimento saudável (GUEDES et al, 2017; BRASIL, 2013).

A sexualidade é um processo natural da vida que envolve aspectos físicos e emocionais promovendo bem estar, e colaborando para uma melhor qualidade de vida (GATTI e PINTO, 2019). Mas, muitas vezes, a sexualdiade na velhice é vista como inexistente, e apesar das limitações fisiológicas, as pessoas envelhecidas têm desejos e são capazes de amar e trocar carícias até o fim da vida (OLIVEIRA et al, 2021; VIEIRA, COUTINHO e SARAIVA, 2016).

Quando a velhice é vista como mais uma fase normal da vida, os estereótipos e preconceitos podem dar lugar ao enaltecimento da vasta experiência que essas pessoas possuem e o rico conhecimento sobre o mundo já adiquiridos (VIEIRA, COUTINHO e SARAIVA, 2016).

Uma grande parcela da sociedade não considera que os idosos podem ter uma vida sexual ativa e não possuem IST’s (KIM et al, 2019). O fato das pessoas mais velhas sofrerem alterações hormonais e físicas pode diminuir a frequência da atividade sexual, mas não findar (OLIVEIRA et al, 2021). Esse tabu faz com que as pessoas da terceira idade não sejam alvo de campanhas de preservativos e prevenção de IST's, deixando-as em situação de risco (EZHOVA et al, 2020; KIM et al, 2019; LYONS, 2017).

O estudo de Kim et al (2019) mostra uma taxa baixa de uso de preservativos e número elevado de parceiros sexuais na população idosa. Em outro estudo, RITTER e UENO (2018), foi identificado que os adultos mais velhos que viveram em um meio onde não era discutida a sexualidade hoje possuem maior envolvimento em práticas sexuais sem preservativos.

É evidente que grande parte dos idosos possui carência de conhecimentos sobre a importância do uso de preservativos e a incidência de IST's nessa fase da vida (GATTI e PINTO, 2019; LIMA et al, 2020). Assim como possuem medo de serem julgados socialmente e pelo próprio parceiro ao falar sobre sexualidade (LIMA et al, 2020).

E - book Tripé do Ensino Superior: Ensino, Pesquisa e Extensão 
Frente a essa realidade, o projeto de extensão Abordando a Sexualidade e Infecções Sexualmente Transmissíveis em um Grupo de Educação em Educação em Saúde para Idosos visou desenvolver uma roda de conversa com idosos para transmitir conhecimentos sobre sexualidade e IST's.

\section{MÉTODO}

O trabalho é um relato de experiência sobre as atividades desenvolvida por graduandas de enfermagem da UFTM, por meio de um projeto de extensão financiada pelo Programa Institucional de Bolsas de Iniciação à Extensão Universitária (PIBEX), em Uberaba - Minas

Gerais. O projeto foi realizado na UAI, semanalmente, durante cinco meses, entre agosto e dezembro de 2018, totalizando 20 encontros.

A UAI é uma unidade da prefeitura de Uberaba que visa promover saúde às pessoas da terceira idade de forma gratuita. São oferecidas atividades recreativas (canto coral, jogos de mesa, baile, bateria), artísticas (pintura em tela, trabalhos manuais), físicas (dança de salão, natação, ginástica, hidroginástica, musculação), área da educação (alfabetização, informática), área de saúde (cabeleireiro, serviço social, psicologia, fisioterapia, enfermaria, terapia ocupacional). Além de ser um dos pontos de telecentro da cidade, onde são desenvolvidas ativi-dades em computadores conectados à internet usando a Tecnologia de Comunicação e Informação (TIC) (PMU).

A Unidade foi escolhida por já desenvolver atividades que visam melhorar a qualidade de vida das pessoas idosas, grande público cadastrado e ampla estrutura física. Para iniciar o trabalho, foi realizado contato com o coordenador da Unidade e solicitado uma sala grande, arejada e bem iluminada, para facilitar as práticas de atividades lúdicas com idosos.

Após a autorização da coordenação, foi realizado divulgação do planejamento do projeto na unidade por cerca de uma semana em diferentes horários do dia. Essa divulgação contou com a distribuição de panfletos (Figura 1), ação de promoção de saúde com aferição de pressão no salão da UAI e distribuição de lanches saudáveis (adequados para pessoas diabéticas e hipertensas), os últimos foram utilizados para aproximação daqueles que ainda não haviam sido abordados. Dessa forma, foi realizado contato com muitos frequentadores da Unidade por onde foi feito o convite para as atividades que seriam desenvolvidas durante o projeto. 
Figura 1. Panfleto.

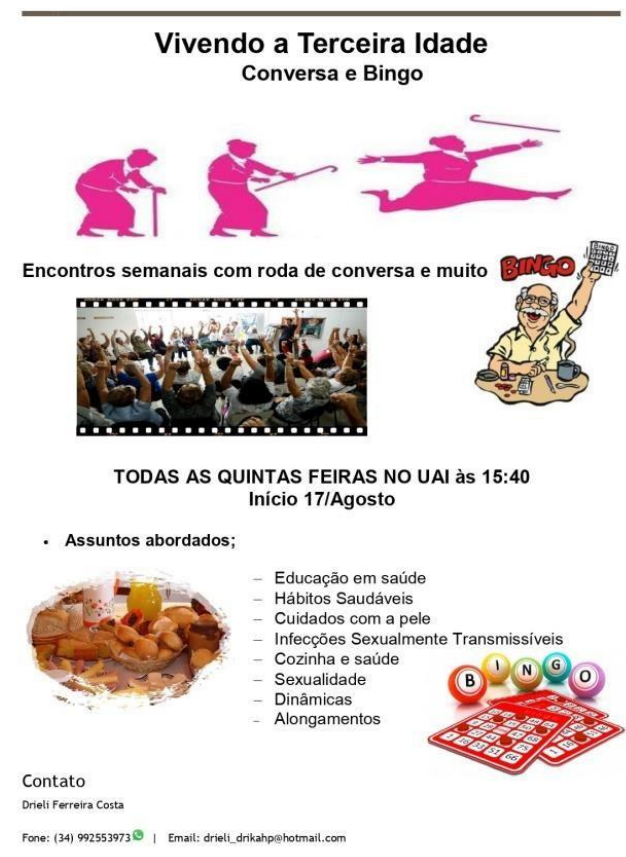

Fonte: Autores, 2018.

Os encontros aconteceram às quintas feiras, com duração de 60 minutos. Para ínciar, todos os participantes se apresentavam, realizavam alongamento como técnica de relaxamento e concentração, desenvolviam uma dinâmica em relação ao tema da aula para integração, discutiam o tema central e por último, era realizado um bingo.

Acerca dos temas, eram escolhidos de forma a contemplar as necessidades da realidade vivenciada pelos idosos. Para isso, a cada encontro os graduandos questionavam sobre os assuntos que eram de interesse para cada idoso, objetivando sanar as dúvidas de todos.

Para a prática metodológica, foi usado como referência o trabalho de Paulo Freire (1968), que mostra a eficácia de trabalhar por meio da investigação, tematização e problematização. Aplicado nessa realidade, investigar consistiu em conversas abertas com os idosos com a finalidade de conhecer as vivências e experiências de todos, identificando os déficits de informações sobre saúde sexual. Logo, era realizada a conscientização das temáticas em questão e, após, a transmissão de informações acerca dos temas levantados pelos idosos.

Como forma de atração para os idosos frequentar os encontros, foi usado a estratégia do jogo de bingo ao final de todos os encontros. Ao término das atividades, era reservado de dez a quinze minutos para realização do bingo, onde o ganhador recebia presentes simbólicos,

\section{E - book Tripé do Ensino Superior: Ensino, Pesquisa e Extensão}


como bijuterias e doces, alguns levados pelos graduandos e outros pelos idosos, o que proporcionava sentimento de participação ativa a eles.

A avaliação da atividade foi realizada semanalmente e em dois momentos distintos. Primeiro, os participantes comentavam sobre os pontos positivos e negativos sobre o tema abordado, a condução das discussões e a forma de transmitir o conhecimento, além disso, dissertavam sobre a absorção das informações discutidas; após, os graduandos responsáveis pela coordenação do grupo avaliavam seu próprio desempenho e o do grupo, a fim de aprimorar a prática com os idosos e melhorar a didática.

\section{RESULTADOS E DISCUSSÃO}

O projeto mostrou resultados positivos desde o início. Diante do contato com a coordenação da unidade, foi possível estreitar a relação com os funcionários promovendo abertura para conversar sobre todas as ações desenvolvidas. Como por exemplo, as dificuldades de cognição que os idosos apresentavam durante a realização de outras atividades. Essa aproximação facilitou a adesão dos participantes, bem como a confiança dos participantes nos condutores da atividade. E os trabalhos desenvolvidos buscavam suprir a carência das participantes através da transmissão de conhecimentos (discussão sobre temas importantes) e práticas de desenvolvimento motor (dinâmicas e alongamentos).

Lima et al (2020), aborda no seu trabalho o receio que os idosos possuem em falar sobre sua sexualidade com medo de julgamentos. As dinâmicas foram importantes estratégias para o grupo de educação em saúde, pois permitiam que os participantes pudessem se sentir mais à vontade na presença dos outros participantes, estreitando os laços entre eles. Essas dinâmicas também fortaleceram o vínculo entre os graduandos e os participantes, possibilitando mais abertura nas falas e questionamentos deles durante as discussões.

Um exemplo de dinâmica foi organizar os participantes em dois círculos com o mesmo número de pessoas, um interno e outro externo, colocoar uma música e pedir para girar os círculos enquanto a música estiver tocando; quando a música parar uma pessoa do círculo interior deve ficar de frente para outra do círculo exterior e fazer perguntas um para outro como: O que mais te deixa feliz? O que você mais admira nas pessoas; O que você mais gosta de fazer?.

Participar de grupos é importante para o desenvolvimento afetivo das pessoas, a socialização e troca de experiências permite maiores perspectivas de vida e melhora da qualidade de vida (SES-SP, 2001). Em consonância, os idosos do projeto demonstraram mais participação ao decorrer das semanas, aumento de alegria e motivação no enfrentamento de 
problemas diários frente aos momentos de relaxamento e promoção de autocuidado vivenciados.

Muitas vezes, a prática de educação em saúde é feita de forma fragmentada, segmentando o conhecimento em diferentes atendimentos médicos (SES-SP, 2001). O projeto visou perpassar o máximo de informações possível acerca da temática sexualidade em idosos. Proporcionando epaço em que os idosos podiam discutir sobre conhecimentos novos e esclarecer dúvidas.

É muito importante para um educador conhecer a realidade do receptor de informações, desenvolver empatia e problematizar sua vivência (SES-SP, 2001). Nesse sentido, os graduanados conseguiram aproximar dos idosos, compartilhando experiências, sem julgamentos, e desenvolvendo escuta ativa. O resultado foi positivo, aumentando a participação durante as atividades e dividindo experiências pessoais com o grupo.

No estudo de Limas et al (2020) foi evidenciado que no atendimento médico, momento propício para discutir assuntos relacionados a saúde, os profissionais de saúde possuem receio de trabalhar sexualidade e prevenção de ISTs com a população idosa. Mas, durante as atividades desenvolvidas houve grande participação dos idosos e interesse pela maioria dos temas estudados. Demonstrando que esse pré conceito de abordar o tema deve ser findado.

Foram abordados diversos temas, como ISTs, sexualidade e hábitos saudáveis, lubrificação, gênero, Papilomavirus Humano (HPV), métodos contraceptivos, exame ginecológico e urológico, infecções que causam feridas, corrimentos e verrugas, apresentação do Centro de Testagem e Aconselhamento (CTA), sexualidade na adolescência, vida adulta e sexualidade na velhice, entre outros. Sendo os temas mais discutidos pelos idosos: menopausa e andropausa, casamentos, infecções urinárias e preservativos.

Concordando com a literatura, foi identificado que a população envelhecida possui muitas dúvidas sobre as mudanças da sexualidade nessa fase da vida (GATTI e PINTO, 2019; LIMA et al, 2020). As orientações correta desse tema pode diminuir estigmas e preparar a pessoa idosa a lidar com sua expressão sexual, beneficiando sua saúde sexual (SRINIVASAN et al, 2020).

Durante a semana do idoso comemorada entre os dias 2 e 6 de outubro, foi desenvolvido uma atividade que buscou conhecer os sonhos dos idosos. Assunto de grande importância quando voltado aos idosos e cercado de crenças que muitas vezes levam a exclusão dos mesmos, uma vez que para nossa sociedade e cultura o idoso deixa de ter sonhos e perspectiva de vida, por envolver planejamentos futuros.

O tema abordado indicou grande relevância para desmistificar a ideia genérica de que a

E - book Tripé do Ensino Superior: Ensino, Pesquisa e Extensão 
terceira idade não possui desejos, planejamentos e sonhos. Assim, a maioria dos idosos abordados mostraram grandes expectativas para o futuro, relatando que o exercício de sonhar é prazeroso na terceira idade. Essa atividade contribuiu para o bem estar e promoção de saúde dos participantes, de acordo com as funções que um profissional de saúde precisa exercer com a população idosa (TAVARES et al, 2016).

Todos os idosos que participaram da atividade assinaram o Termo de Autorização de Uso da Imagem. E, algumas falas, foi percebida a importância do sonhar na vida dessas pessoas, impulsionando-as a ter um objetivo e uma conquista a ser realizada. A ação buscou homenagear os idosos por meio de uma atividade lúdica e dinâmica, proporcionando diversão aos participantes, que apresentaram um pouco da sua história de vida, sua vivência da terceira idade e os seus sonhos ainda não alcançados, como demostrado em algumas das imagens a seguir:

Imagem 1. Sonhando na Terceira Idade.

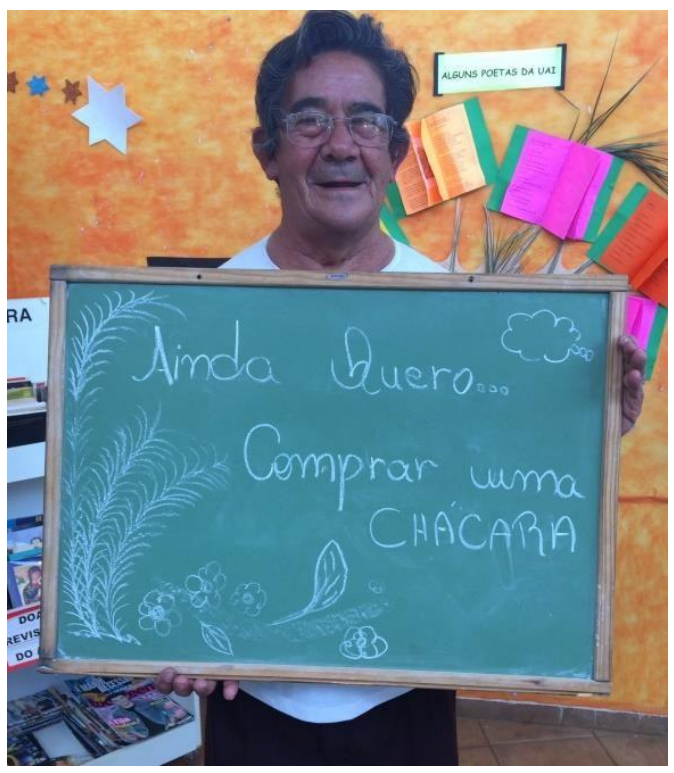

Fonte: Autores, 2018.
Imagem 2. Sonhando na Terceira Idade.

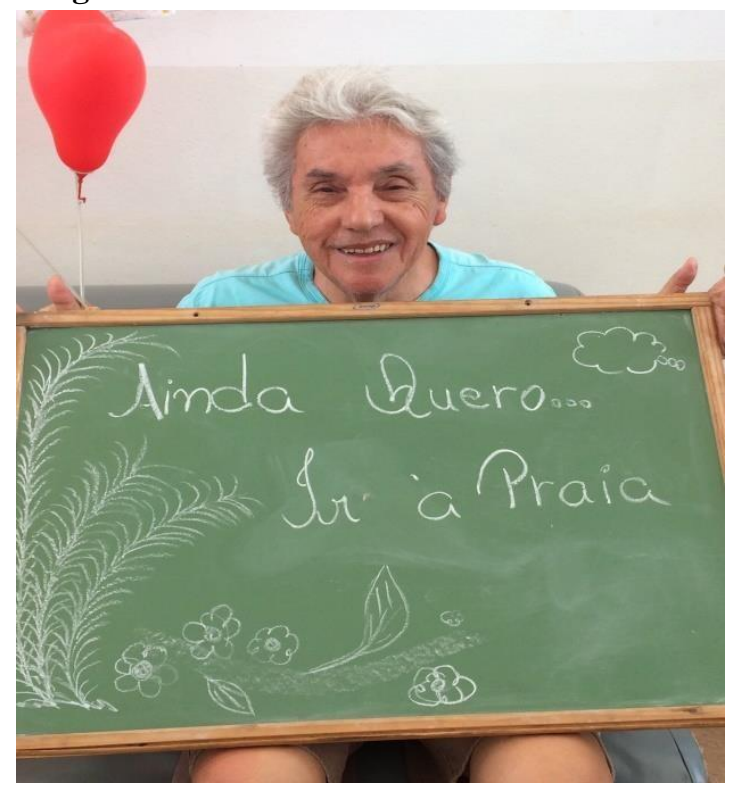

Fonte: Autores, 2018. 
Imagem 3. Sonhando na Terceira Idade.

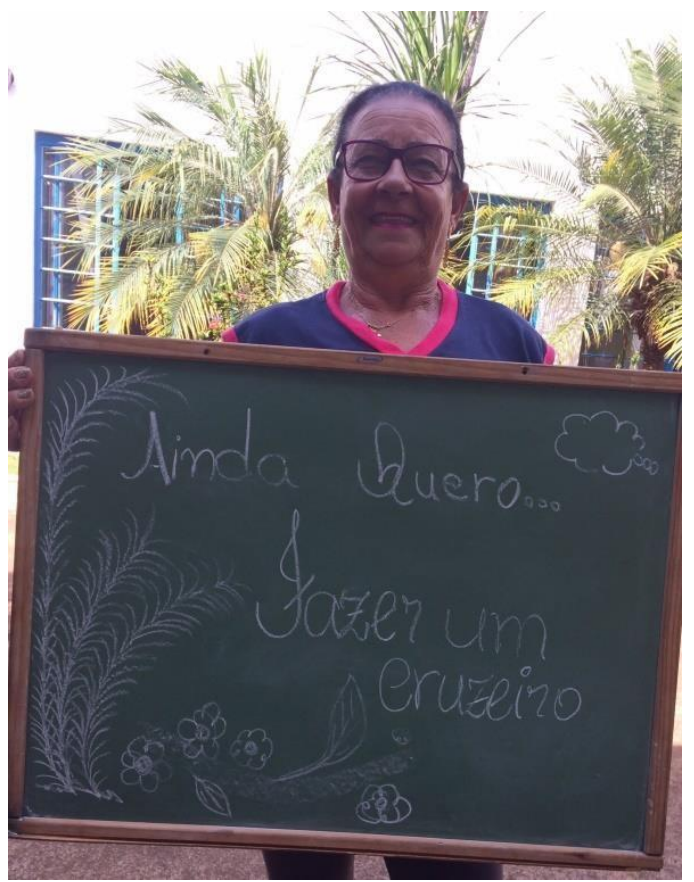

Fonte: Autores, 2018.
Imagem 4. Sonhando na Terceira Idade.

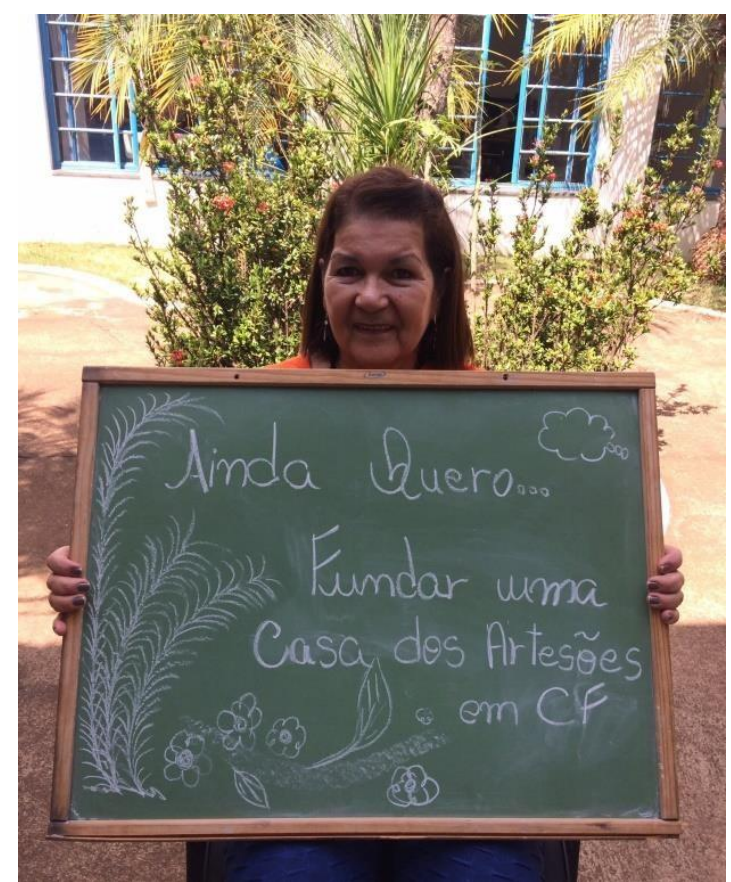

Fonte: Autores, 2018.

\section{CONCLUSÃO}

O envelhecimento populacional esta acontecendo de forma mundial, e os cuidados com os idosos precisam ser discutidos cada vez mais. É necessário atenção nas reais necessidades que essa fase da vida necessita para promover bem estar e promoção de saúde na velhice.

Dentro desse contexto, a sexualidade é um importante fator a ser estudado. O estigma de idosos serem assexuais pode fazer a velhice ser vivida com medo e receio ou muitas das vezes, ser anulada. de coerções sociais e até mesmo do parceiro, o que deixa a sexualidade inativa.

Contudo, intervenção que mescla troca de experiências e momentos de descontração se mostrou eficaz. Trabalhar educação em saúde pode trazer vários benéficios, como promoção de bem estar, melhora da qualidade de vida e incentivo ao autocuidado. Sendo assim, o presente estudo demonstra resultados positivos na transmissão de conhecimentos por meio de uma roda de conversas com idosos.

\section{REFERÊNCIAS}

ANACLETO, G. M. C.; AQUINO, R. C.; REBUSTINI, F. Quality of life in the elderly in a stretching program. Revista Kairós - Gerontologia, v. 1, n. 20, São Paulo, 2017.

Brasil. Ministério da Saúde. Estatuto do Idoso / Ministério da Saúde - 3. ed., 2. reimpr. - Brasília : Ministério da Saúde, 2013. 70 p.

ECHOVA, L. et al. Barriers to older adults seeking sexual health advice and treatment: A scoping review. International Journal of Nursing Studies, v. 107, 2020. 
GATTI, M. C.; PINTO, M. J. C. Velhice ativa: a vivência afetivo-sexual da pessoa idosa.

Períodicos Eletrônicos em Psicologia, v. 16, n. 2, 2019. http://dx.doi.org/10.32467/issn.199821492v16n2p133-159

GUEDES, M. B. O. G. et al. Apoio social e o cuidado integral à saúde do idoso. Pshysis, v. 27, n. 4, p. 1185-1204, 2017.

IBGE- Instituto Brasileiro de Geografia e Estatística. Projeção da população do Brasil e das Unidades da Federação, 2021. Disponível em: <

https://www.ibge.gov.br/apps/populacao/projecao/>. Acesso em 30 de agosto de 2021.

KIM, H. Y. et al. Comportamento sexual e infecções sexualmente transmissíveis na população idosa da Coreia do Sul. Investigative and Clinical Urology, v. 60, n. 3, p. 202-209, 2019.

LIMA, I. C. C. et al. Sexualidade na terceira idade e educação em saúde: um relato de experiência. Revista de Saúde Pública do Paraná, v. 1, n.3, p. 137-143, 2020.

LYONS, A. et al. Sexually active older Australian's knowledge of sexually transmitted infections and safer sexual practices. Australian and New Zealand of Public Health, v. 41, n. 3, p. 259-261, 2017.

OLIVEIRA, P. R. S. P. et al. Sexualidade de idosos participantes de um centro de convivência. Revista Online de Pesquisa, v. 13, n. 13, p. 1075-1081, 2021.

PMU - Prefeitura Municipal de Uberaba. Unidades Municipais. Disponível em: <http://uberaba.mg.gov.br/portal/conteudo,10248>

RITTER, L. J.; UENO, K. Same- N. ex Contact and Lifetime Sexually Transmitted Disease Diagnoses Among Older Adults. Journal of Aging and Health, v. 34, n. 6, 2019.

SERINIVASAN, S. et al. Sexuality and the Older Adult. Current Psychiatry Reports, v. 21, n. 97, 2019. https://doi.org/10.1007/s11920-019-1090-4

SES-SP - Secretária do Estado de Saúde de São Paulo. Manual Para Operacionalização das Ações Educativas no SUS. Educação em Saúde Planejando as Ações Educativas: Teoria e Prática. São Paulo (SP): Secretaria do Estado de Saúde de São Paulo; 2001.

TAVARES, M. F. L et al. A promoção de saúde no ensino profissional: desafios na Saúde e a necessidade de alcançar outros setores. Ciência e Saúde Coletiva, v. 6, n. 21, p. 1799-1800, 2016.

VIEIRA, K. F. L.; COUTINHO, M. P. L.; SARAIVA, E. R. A. A Sexualidade Na Velhice: Representações Sociais de Convivência. Revista Psicologia, Ciência e Profissão, n. 36, v. 1, 2016. https://doi.org/10.1590/1982-3703002392013 